\title{
CREEP DEFORMATION MECHANISMS IN SOME MODERN SINGLE-CRYSTAL SUPERALLOYS
}

\author{
J.X. Zhang, T. Murakumo, H. Harada, Y. Koizumi, T. Kobayashi
}

High Temperature Materials 21 Project, National Institute for Materials Science (NIMS), 1-2-1 Sengen, Tsukuba, Ibaraki 305-0047, Japan

Keywords: Superalloys, Creep Mechanism, Dislocations, Ru, Single Crystal

\begin{abstract}
The creep deformation in some modern superalloys was studied to clarify the creep mechanisms under a high-temperature and low-stress condition and a low-temperature and high-stress condition. At a temperature of $1100^{\circ} \mathrm{C}$ and a stress of $137 \mathrm{MPa}$ or at a temperature of $1000^{\circ} \mathrm{C}$ and a stress of $245 \mathrm{MPa}$, the large $\gamma / \gamma^{\prime}$ lattice misfit in negative with the addition of Mo leads to the formation of dense interfacial dislocation networks. These dislocation networks are effective in strengthening the alloys during creep by preventing the penetration of the $\gamma$ dislocations into the $\gamma^{\prime}$ phase. At a temperature of $800^{\circ} \mathrm{C}$ and stresses of 735 $\mathrm{MPa}$ and $607 \mathrm{MPa}$, the improved creep properties of the superalloys are due to the solid solution strengthening by the addition of $\mathrm{Ru}$.
\end{abstract}

\section{Introduction}

The strength of Ni-base single-crystal (SC) superalloys has been improved by the addition of various strengthening elements. However, TCP phases, which decrease the creep strength, tend to appear when these additions exceed their solubility limit. For example, Re, Mo, W and Ta are important strengthening elements in superalloys; however, the formation of the TCP phases reduces the strengthening effect considerably. To stabilize the microstructure, $\mathrm{Ru}$ is added to 4th generation Ni-base singlecrystal superalloys (e.g., TMS-138) [1,2]. In this paper, the creep deformation mechanisms of Ru-containing single-crystal alloys under high-temperature low-stress and low-temperature highstress creep conditions are studied.

\section{Experimental}

In this study, five SC superalloys (Table 1) designed by NIMS were used. TMS-75 and TMS-138 are 3rd and 4th generation SC alloys, respectively, and TMS-162 is a newly developed alloy. (Work regarding to the alloy development is to be presented at the same symposium (Superalloys 2004)).

All the creep tests were carried out along the [001] axis under different temperatures and stresses. The high-temperature lowstress creep tests were carried out at $1100^{\circ} \mathrm{C}$ and $137 \mathrm{MPa}$. The low-temperature high-stress creep tests were conducted at $800^{\circ} \mathrm{C}$ under stresses of $735 \mathrm{MPa}$ and $607 \mathrm{MPa}$ for superalloys TMS-75, TMS-138, and TMS-162. For the purposes of comparison, the alloy TMS-162 was also tested at the condition of $1000^{\circ} \mathrm{C}$ and 245 $\mathrm{MPa}$. This condition is referred as moderate-temperature and moderate-stress creep in this paper.

\section{Results}

3.1 High-temperature low-stress creep $\left(1100^{\circ} \mathrm{C}, 137 \mathrm{MPa}\right)$

Generally, a high-temperature low-stress creep mechanism is different from that under low-temperature high-stress. Under this condition, the rafted structure can be built up and dislocation climbing along the longitudinal direction becomes difficult.

Table 1 Nominal composition of the alloys investigated (wt\%)

\begin{tabular}{|c|c|c|c|c|c|c|c|c|c|c|}
\hline & Co & Cr & Mo & W & Al & Ta & Hf & Re & Ru & Ni \\
\hline TMS-75 & 12.0 & 3.0 & $\mathbf{2 . 0}$ & 6.0 & 6.0 & 6.0 & 0.1 & 5.0 & $\mathbf{0}$ & Bal. \\
\hline TMS-75(+Mo) & 6.0 & 3.0 & $\mathbf{3 . 0}$ & 6.0 & 6.0 & 6.0 & 0.1 & 5.0 & $\mathbf{0}$ & Bal. \\
\hline TMS-75(+Ru) & 11.8 & 3.0 & $\mathbf{2 . 0}$ & 5.9 & 5.9 & 5.9 & 0.1 & 4.9 & $\mathbf{1 . 6}$ & Bal. \\
\hline TMS-138 & 5.9 & 2.9 & $\mathbf{2 . 9}$ & 5.9 & 5.9 & 5.6 & 0.1 & 4.9 & $\mathbf{2 . 0}$ & Bal. \\
\hline TMS-162 & 5.8 & 2.9 & $\mathbf{3 . 9}$ & 5.8 & 5.8 & 5.6 & 0.1 & 4.9 & $\mathbf{6 . 0}$ & Bal. \\
\hline
\end{tabular}


Consequently, the gliding dislocations gradually start cutting into the $\gamma^{\prime}$ phase as superdislocations [3]. However, this situation can be prevented effectively by the $\gamma / \gamma^{\prime}$ interfacial dislocation networks that resist the gliding dislocations from passing through.

The five superalloys above show considerably different creep properties (Fig. 1). The new alloy TMS-162 has the smallest minimum creep rate and longest creep-rupture life of all the five superalloys. In contrast, the alloy TMS- $75(+\mathrm{Ru})$ demonstrates the largest minimum creep rate and shortest creep-rupture life.

The $\gamma / \gamma^{\prime}$ interfacial dislocation spacing was measured after creep rupture. To avoid the influence of the tertiary creep deformation, the TEM specimens were taken from a position of $3 \mathrm{~mm}$ away from the necked region. In this way, we observe the microstructure still in the secondary creep region. An approximately linear relationship (Fig. 2) exists between the logarithm of minimum creep rate and the interfacial dislocation spacing in TMS-75, TMS-75(+Mo), TMS-75(+Ru), TMS-138, and TMS-162. The minimum creep rate decreases with the decrease of the dislocation spacing in the $\gamma / \gamma^{\prime}$ interface. Of the five superalloys, TMS-162 has

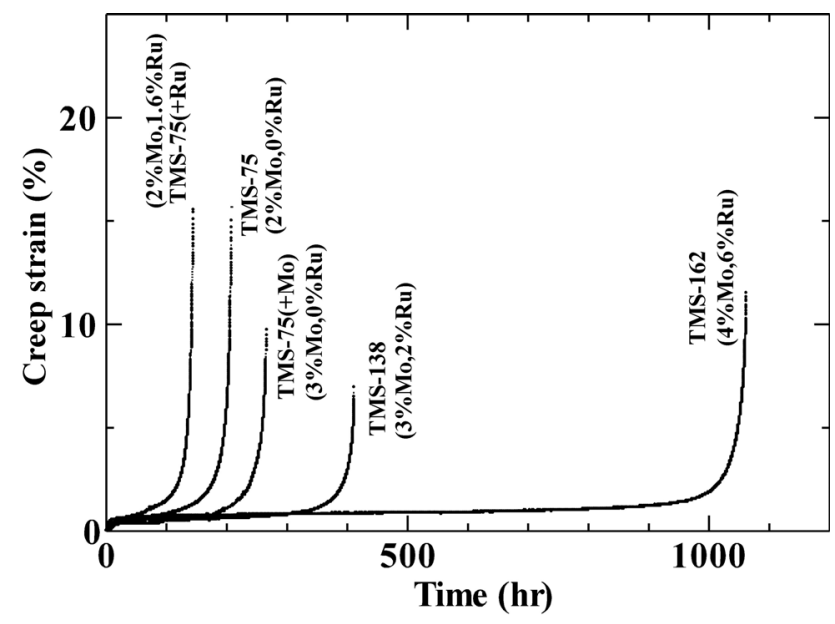

Fig. 1 Creep curves of superalloys TMS-75, TMS-75(+Ru), TMS-75(+Mo), TMS-138, and TMS-162 tested at $1100^{\circ} \mathrm{C}$ and $137 \mathrm{MPa}$.

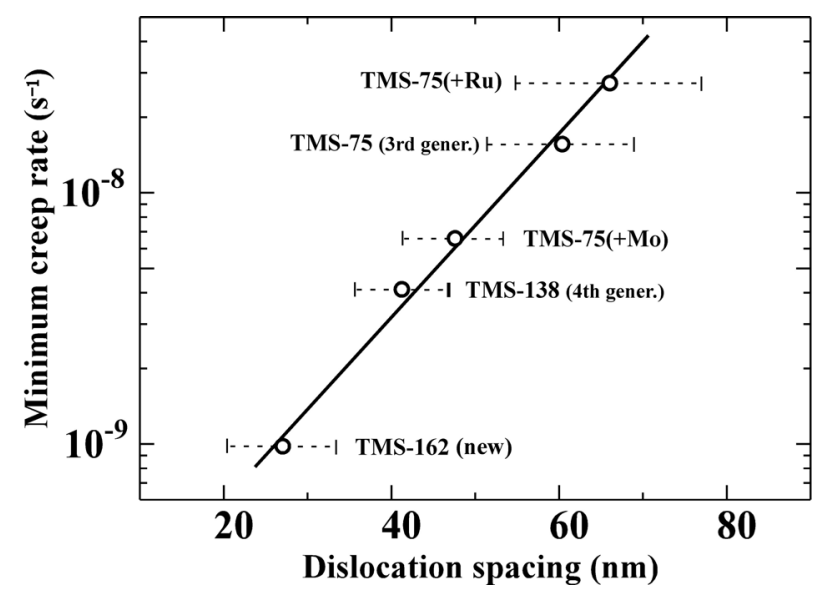

Fig. 2 Minimum creep rates of superalloys TMS-75, TMS-75 (+Ru), TMS-75(+Mo), TMS-138, and TMS-162 as a function of their interfacial dislocation spacing.
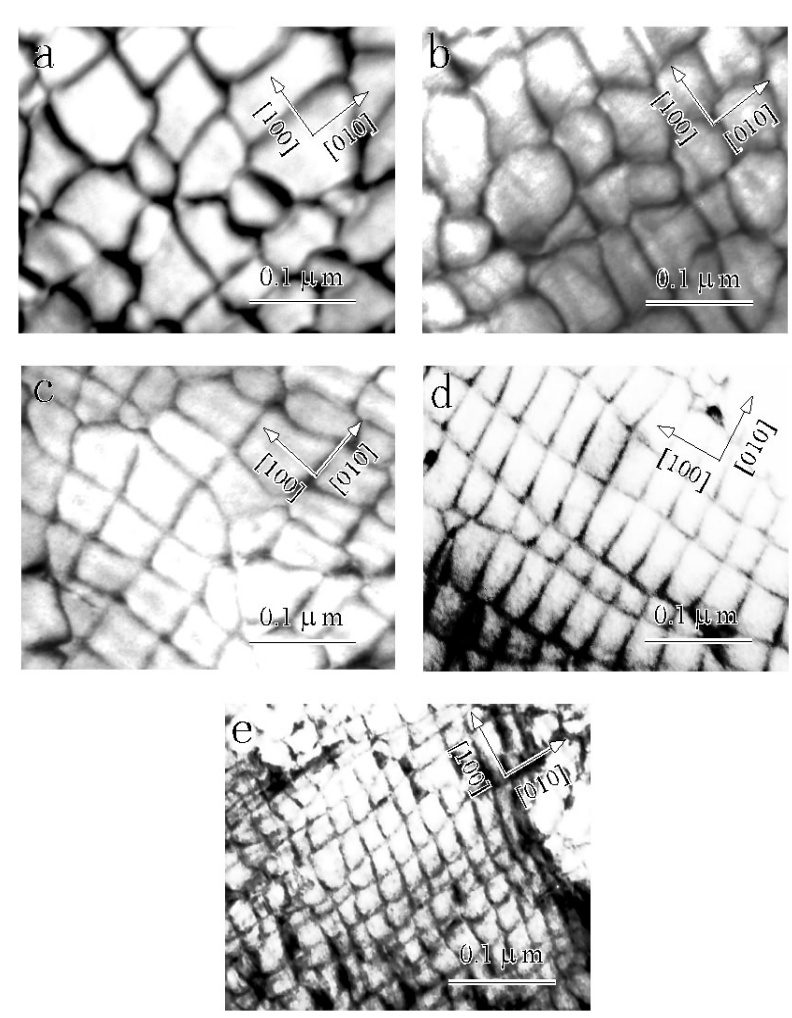

Fig. 3 Morphology of the $\gamma / \gamma^{\prime}$ interfacial dislocation networks in (a) TMS-75(+Ru), (b) TMS-75, (c) TMS-75(+Mo), (d)

TMS-138, and (e) TMS-162 after creep rupture at $1100^{\circ} \mathrm{C}$ and $137 \mathrm{MPa}$.

the smallest interfacial dislocation spacing and minimum creep rate. These dense interfacial dislocations can prevent the glide dislocations from cutting the rafted $\gamma / \gamma^{\prime}$ structure.

After creep rupture, the interfacial dislocation networks in TMS-75(+Ru) and TMS-75 are irregular and look like the deformed meshes (as shown in Fig. 3(a,b)). The dislocation lines roughly lie in the $\langle 100\rangle$ directions on average. In TMS-138, TMS-162 (Fig. 3(d,e)), and even in TMS-75(+Mo) (Fig.3(c)), the dislocations in the squared networks are parallel to the $<100>$ directions with their Burgers vectors parallel to the octahedral slip vectors. In general, the dislocation networks in the squared form can prevent the glide dislocations more effectively than the hexagonal meshes, because the formation of new segments by dislocation reactions during creep will result in an increased possibility of a glissile dislocation in $\gamma$ channel to pass through the interfacial dislocation networks [4].

Another important characteristic of the $\gamma / \gamma^{\prime}$ interfacial dislocation networks is the difference in dislocation spacing distributions. In TMS-75, TMS-75(+Ru), and TMS-75(+Mo), the interfacial dislocation spacing is distributed in a wide range (Fig. 4(a,b,c)), whereas, in TMS-138 and TMS-162 (Fig. 4(d,e)), the dislocation spacing has a narrow distribution range. With the increase of the lattice misfit in the negative $\left(a_{\gamma}>a_{\gamma^{\prime}}\right)$, the interfacial dislocations tend to become homogeneously arranged, due to the stronger elastic interaction between the dislocations closer to each other. In this respect, the homogeneous distribution of the interfacial dislocations in TMS-138 and TMS-162 can 


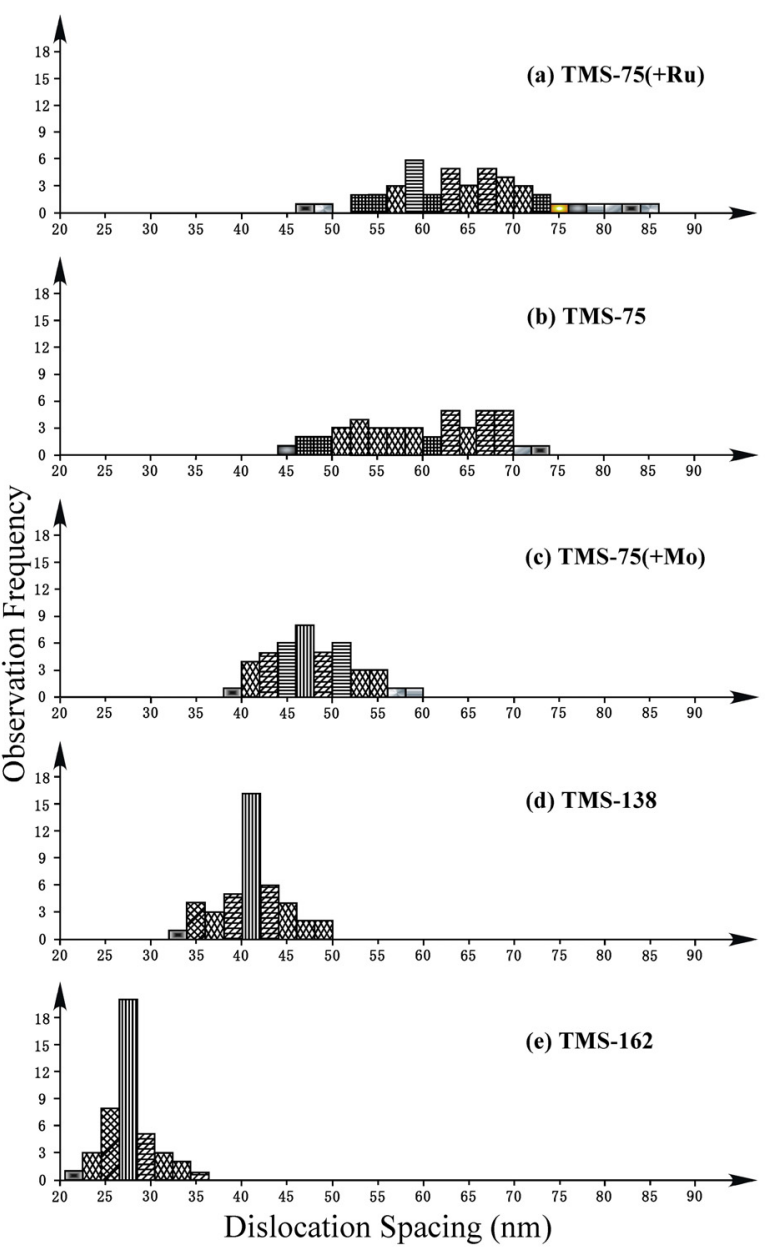

Fig. 4 Distribution of $\gamma / \gamma^{\prime}$ interfacial dislocation spacing in (a) TMS-75(+Ru), (b) TMS-75, (c) TMS-75(+Mo), (d) TMS-138, and (e) TMS-162.

effectively prevent the glide dislocations from cutting the $\gamma / \gamma^{\prime}$ rafted structure, because the inhomogeneously distributed interfacial dislocations may let the glissile dislocations to pass through the networks at those positions with considerable spacing [4].

To study the effects of the lattice misfit on the dislocation motion, two types of superalloys were interrupted during creep test. TMS $-75(+\mathrm{Ru})$ has a small lattice misfit in negative, $-0.16 \%$; whereas, TMS-138 has a relatively large lattice misfit, $-0.33 \%$, both determined by X-ray measurement at $1100^{\circ} \mathrm{C}$. (Note: the lattice misfit of the alloy TMS-75 was measured to be $-0.18 \%$ at the same temperature).

For the TMS-75(+Ru) alloy with a smaller misfit, a gliding dislocation cannot bow into the $\gamma$ channel when it meets $\gamma^{\prime}$ cuboids (Fig. 5(a,b)). Stereomicroscopy analysis showed that the dislocation $\mathrm{AB}$ is moving on its corresponding (111) gliding plane. Two parts (marked by ' $\mathrm{s}$ ' and ' $\mathrm{t}$ ') of the dislocation are bowing into the $\gamma$ channel and its third part (marked by 'pq') is still in the vertical $\gamma$ channel. Due to the small $\gamma / \gamma^{\prime}$ lattice misfit, the driving force for the dislocation to enter the $\gamma$ channel is not enough for overcoming the Orowan resistance. The dislocation can only move by a general climb around the cuboids, as previously proposed [57], while particle cutting or Orowan bowing, which predominates at higher stresses and/or lower temperatures, was absent. The high-temperature low-stress creep condition favors the climbing mechanism.

For the TMS-138 alloy with a larger misfit, the dislocations bow through the horizontal $\gamma$ channels and leave long narrow loops in the $\gamma$ channels (Fig. 5(c,d)). These dislocations show an obvious slip character as well as a zigzagged cross slip character.

The motion of dislocations in $\gamma$ channels is mainly determined by the Orowan resistance, misfit stress, and applied stress [8]. The average matrix thickness is about $70 \mathrm{~nm}$ for the two superalloys. The Orowan resistance for dislocation movement is about 131 $\mathrm{MPa}$. If the resolved shear stress is high enough to overcome the local Orowan resistance of the $\gamma$ channels, the dislocations can be pushed into the channels. The force comes from a combined result of applied tensile stress and internal $\gamma / \gamma^{\prime}$ misfit stress. The finite element method was used to evaluate the misfit stress in the $\gamma$ channel.

The actual shear stresses were calculated to be $106.6 \mathrm{MPa}$ and 162.1 $\mathrm{MPa}$ for TMS-75(+Ru) and TMS-138, respectively. Obviously, in TMS-75(+Ru), dislocations with such a low resolved shear stress cannot overcome the Orowan resistance and fail to glide through the $\gamma$ matrix channels; however, they can move mostly by climbing. In contrast, in TMS-138, the resolved shear stress is higher than the Orowan resistance, which results in the rapid formation of wide extensions of dislocations in the horizontal matrix channels. A critical lattice misfit of $-0.25 \%$ was calculated for the penetration of glide dislocations through the $\gamma$ channel.

The specimens interrupted at 60 hours during creep showed that the $(001) \gamma / \gamma^{\prime}$ interfacial dislocation networks in TMS-75(+Ru) are not so perfect and that many superdislocations exist in the $\gamma^{\prime}$ phase (Fig. 6(a)). This means that the interfacial dislocations cannot effectively prevent the glide dislocations from cutting the $\gamma^{\prime}$ phase. In contrast, the $\gamma / \gamma^{\prime}$ interfacial dislocation networks in TMS-138 are perfect and have few superdislocations in the $\gamma^{\prime}$ phase (Fig. 6(b)). This observation gives a clear indication that the minimum creep rate bears a relation to the cutting events of the $\gamma^{\prime}$ phase, as analyzed from Fig. 2.

\subsection{Moderate-temperature moderate-stress creep $\left(1000^{\circ} \mathrm{C}, 245\right.$ MPa)}

Figure 7 shows the creep curve of TMS- 162 at $1000^{\circ} \mathrm{C}$ and 245 $\mathrm{MPa}$. For comparison, the creep curve of TMS- 162 at $1100^{\circ} \mathrm{C}$ and $137 \mathrm{MPa}$ was also added. During the primary creep, the alloy can rapidly form a rafted structure at $1100^{\circ} \mathrm{C}$ and $137 \mathrm{MPa}$. However, the rafting process is slow at $1000^{\circ} \mathrm{C}$ and $245 \mathrm{MPa}$. This difference is attributed to the effect of the temperature on the diffusion rate of the elements. At the steady creep stage, the minimum creep rate of the alloy at $1000^{\circ} \mathrm{C}$ under $245 \mathrm{MPa}$ is obviously larger than that at $1100^{\circ} \mathrm{C}$ under $137 \mathrm{MPa}$. The observation by scanning electron microscopy shows that the $\gamma / \gamma^{\prime}$ rafted structure was well formed during creep in the alloy under the two kinds of creep conditions [9]. The TEM measurement showed that the $\gamma / \gamma^{\prime}$ interfacial dislocation spacing $(\sim 24 \mathrm{~nm})$ at the creep condition of $1000^{\circ} \mathrm{C}$ and $245 \mathrm{MPa}$ is smaller than that at $1100^{\circ} \mathrm{C}$ under $137 \mathrm{MPa}(\sim 27 \mathrm{~nm})$. This is due to the higher stress 

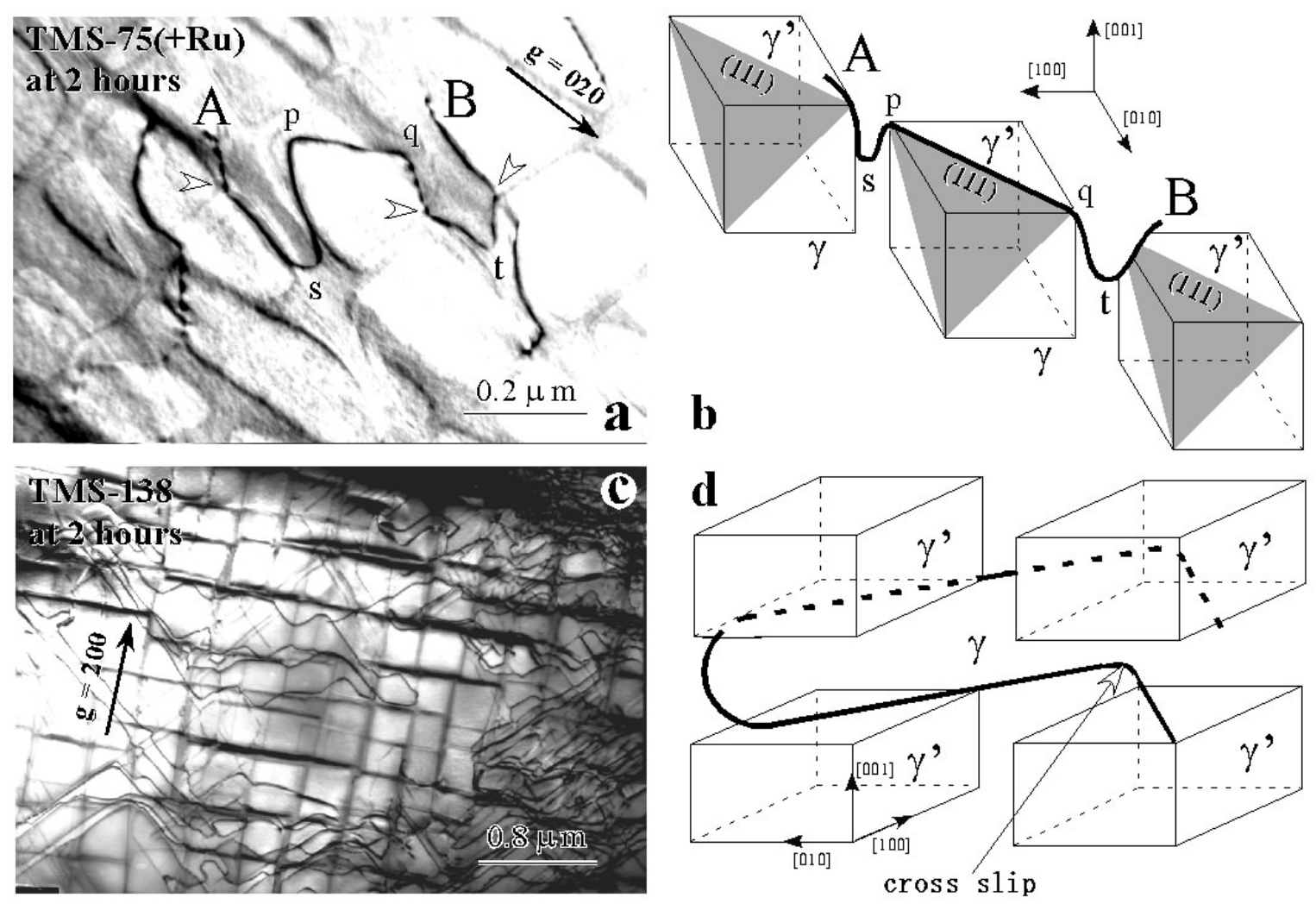

Fig. 5 Configuration of dislocations in (a) TMS-75(+Ru) and (c) TMS-138 interrupted at 2 hours during creep at $1100^{\circ} \mathrm{C}$ and $137 \mathrm{MPa}$. (b)(d) Schematic illustrations to show the dislocation movement in (a) and (c), respectively. Beam // [001].

exerted on the tensile sample in the former case than in the latter case.

Figures $8 \mathrm{a}$ and $\mathrm{b}$ show the microstructure of TMS-162 after creep rupture at $1100^{\circ} \mathrm{C}$ and $137 \mathrm{MPa}$ and at $1000^{\circ} \mathrm{C}$ and 245 $\mathrm{MPa}$, respectively. The superdislocation density in the $\gamma^{\prime}$ phase under the latter creep condition is higher than that under the former condition. On the other hand, for the creep at $1100^{\circ} \mathrm{C}$ and $137 \mathrm{MPa}$, many superdislocations are of the Burgers vector $\mathrm{b}=$ $<011>$; whereas, for the creep at $1000^{\circ} \mathrm{C}$ under $245 \mathrm{MPa}$, many superdislocations have a segmented structure with Burgers vector $\mathrm{b}=\langle 001>$. The $<011>$ superdislocations are oriented in an inclination state in the TEM foil, while the $<001>$ superdislocations are parallel to the (001) plane of the TEM specimen.

\subsection{Low-temperature high-stress creep $\left(800^{\circ} \mathrm{C}, 735 \mathrm{MPa}\right.$ and $607 \mathrm{MPa})$}

Figure 9 shows the creep curves of TMS-75, TMS-138, and TMS- 162 at $800^{\circ} \mathrm{C}$ and $735 \mathrm{MPa}$. Obviously, the addition of $\mathrm{Ru}$ and Mo decreases the primary creep strain and increases the creep rupture life.

Figure 10 shows the microstructure of these three alloys after creep rupture at $800^{\circ} \mathrm{C}$ and the stresses of $735 \mathrm{MPa}$ and $607 \mathrm{MPa}$. The super stacking faults (SSFs) [10] were frequently observed in the three alloys with the applied stress of $735 \mathrm{MPa}$ (Fig. 10(a-c)). A similar microstructure was also obtained in TMS-75 after creep at $607 \mathrm{MPa}$ (Fig. 10(d)). However, in TMS-138 and TMS-162 tested at $607 \mathrm{MPa}$, SSFs were not observed, and the density of dislocations in the $\gamma$ channel was quite low (Fig. 10(e-f)).

\section{Discussion \\ 4.1 High-temperature low-stress creep}

The dissociation of superdislocations observed during creep at relatively lower temperature usually involves stacking faults, while the antiphase boundary dissociation is generally observed during creep at higher temperature [9]. However, in the present study, the addition of the elements $\mathrm{Mo}$ and $\mathrm{Ru}$ is strikingly interesting. For the high-temperature low-stress creep, the possible compositional effects should play a role, to varying degrees, in determining the strength of the alloy at the testing conditions. First, the change in APB (antiphase boundary) energy and SF (stacking fault) energy associated with the alloying additions should be considered, since the energy required to form APB and $\mathrm{SF}$ is an important factor in a material's resistance to deformation. The addition of Mo can decrease the APB energy and the SF energy [11,12]. Thus, the threshold resolved shear stress for a dislocation to enter the $\gamma^{\prime}$ particles, which is proportional to the APB energy, would fall down. From the viewpoint of APB energy and SF energy, the contribution of Mo for the strengthening of the alloy is negative. Similarly, the addition of $\mathrm{Ru}$ has no measurable effect on the APB energy and SF energy [13]; thus, it is difficult to explain the enhanced creep property according to the change in APB energy and SF energy. 
A good phase stability, although being essential for the superior creep strength, should not be regarded as a main factor for the strength of TMS-162, since along with TMS-162, TMS-75, TMS$75(+\mathrm{Ru})$ and TMS-138 are also TCP free, and yet TMS-162 is the strongest.
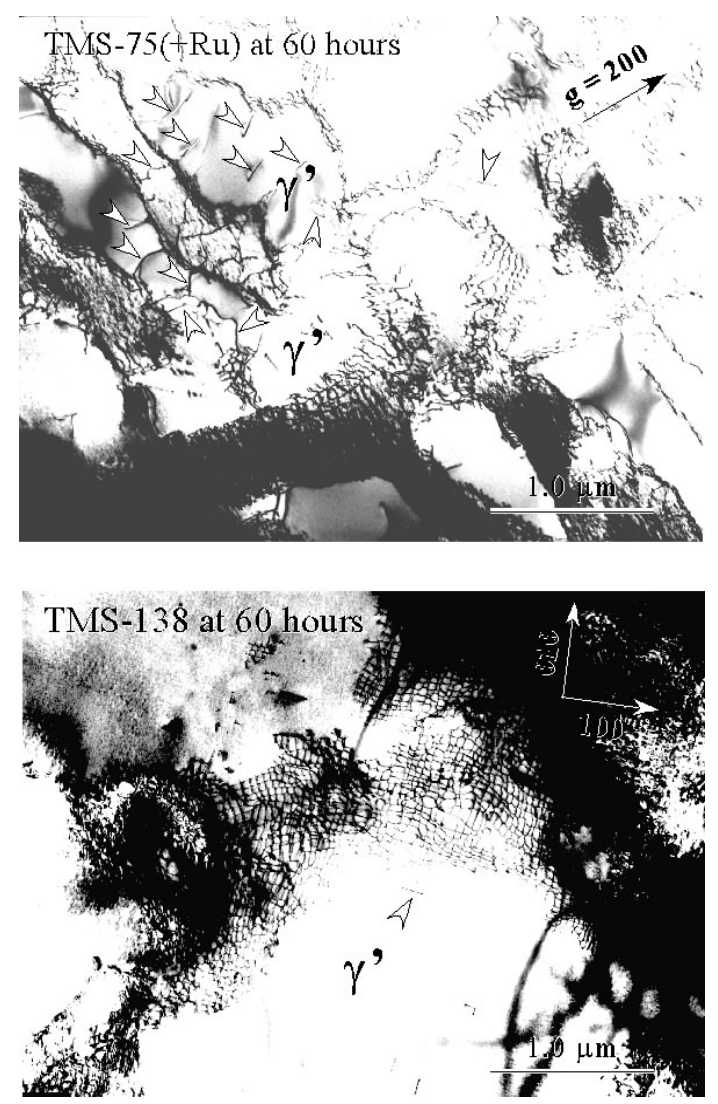

Fig. 6 Dislocation configurations in TMS-75(+Ru) and TMS-138 tested at $1100^{\circ} \mathrm{C}$ and $137 \mathrm{MPa}$ and interrupted at 60 hours. A lot of superdislocations exist in the $\gamma^{\prime}$ phase in TMS-75 $(+\mathrm{Ru})$ (indicated by arrows). Beam // [001].

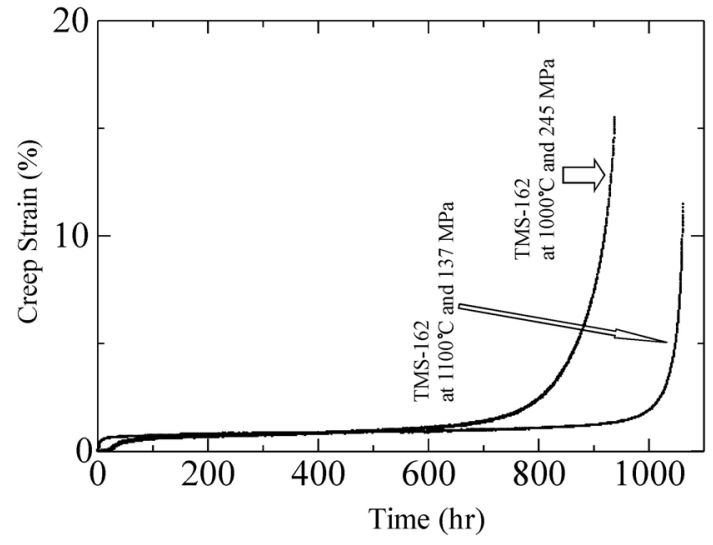

Fig. 7 Creep curves of superalloy TMS-162 tested at $1000^{\circ} \mathrm{C}$ and $245 \mathrm{MPa}$. For comparison, the creep curve of the alloy at $1100^{\circ} \mathrm{C}$ and $137 \mathrm{MPa}$ is also added.
The large lattice misfit can promote the formation of a rafted $\gamma / \gamma^{\prime}$ structure and also result in dense $\gamma / \gamma^{\prime}$ interfacial dislocation networks. The large lattice misfit due to the addition of Mo in TMS-75(+Mo), TMS-138 and TMS-162 is caused by the
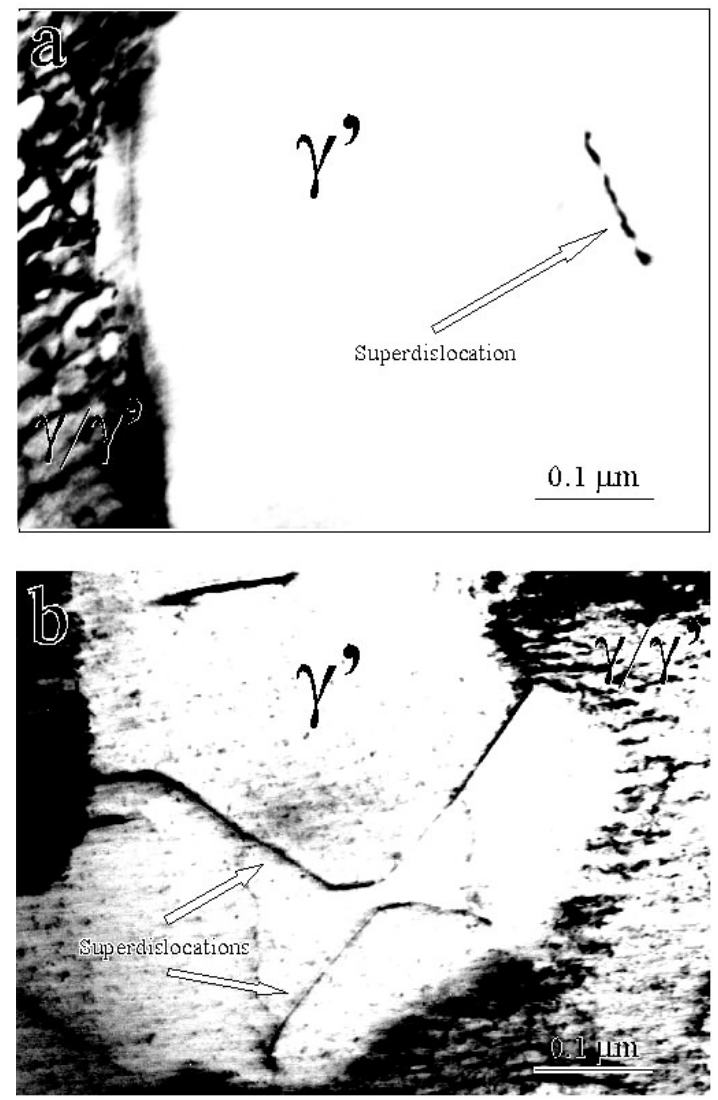

Fig. 8 Superdislocations in TMS-162 after creep rupture (a) at $1100^{\circ} \mathrm{C}$ under $137 \mathrm{MPa}$, and (b) at $1000^{\circ} \mathrm{C}$ under $245 \mathrm{MPa}$. Beam // [001].

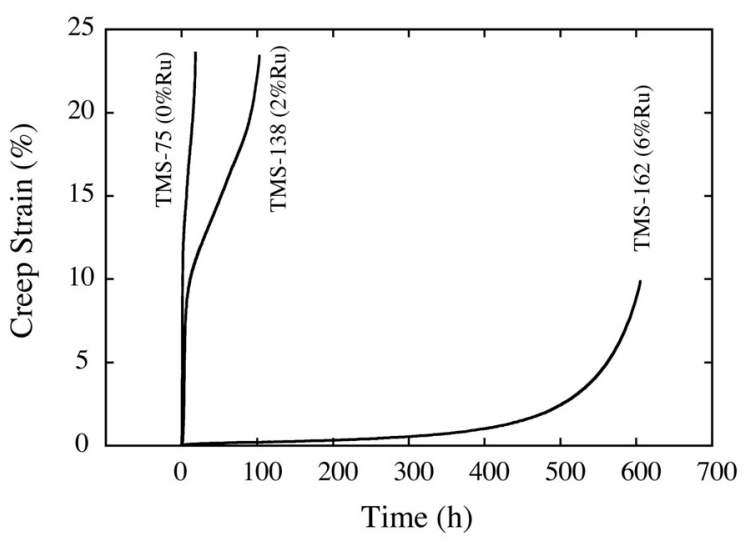

Fig. 9 Creep curves of superalloys TMS-75, TMS-138, and TMS-162 (all containing $5 \mathrm{wt} \% \mathrm{Re}$ but a different amount of $\mathrm{Mo}$ and $\mathrm{Ru}$ ) tested at $800^{\circ} \mathrm{C}$ and $735 \mathrm{MPa}$. 
partitioning behavior of the element Mo, which has a strong preference to partition into the $\gamma$ phase independent of the $\mathrm{Ru}$ addition [14], and the large radius of the Mo atom.

In view of the effects of (1) APB energy and SF energy, (2) phase stability, and (3) interfacial dislocation density due to the addition of Mo, the interfacial dislocation networks play a key role during the high-temperature low-stress creep process, especially at the steady creep stage.

The cutting of the rafted structure still has a close relation to the damage of the specimen at the tertiary stage. It was found that double slip on glide planes $(1 \overline{1} 1)$ and $(\overline{1} 11)$ caused the necked area [15]. The dislocation movement drives the rafted $\gamma / \gamma^{\prime}$ interface closer to a $\{111\}$ glide plane, as a result, accelerates the creep deformation and causes the large increase in strain rate before failure.

Our previous study showed that the microstructure and the creep strength of an interrupted specimen at the early tertiary stage can be recovered by a re-solution treatment followed by a two-step ageing treatment [16]. This confirmed that the initiation of the tertiary stage is caused by the degeneration of the rafted structure. On the contrary, the failure mechanism caused by the creep void formation and possible cavitation damage around casting porosity can be excluded for the present specimens, since a tertiary creep initiated by the formation of voids cannot be recovered by the reheat treatment mentioned above.
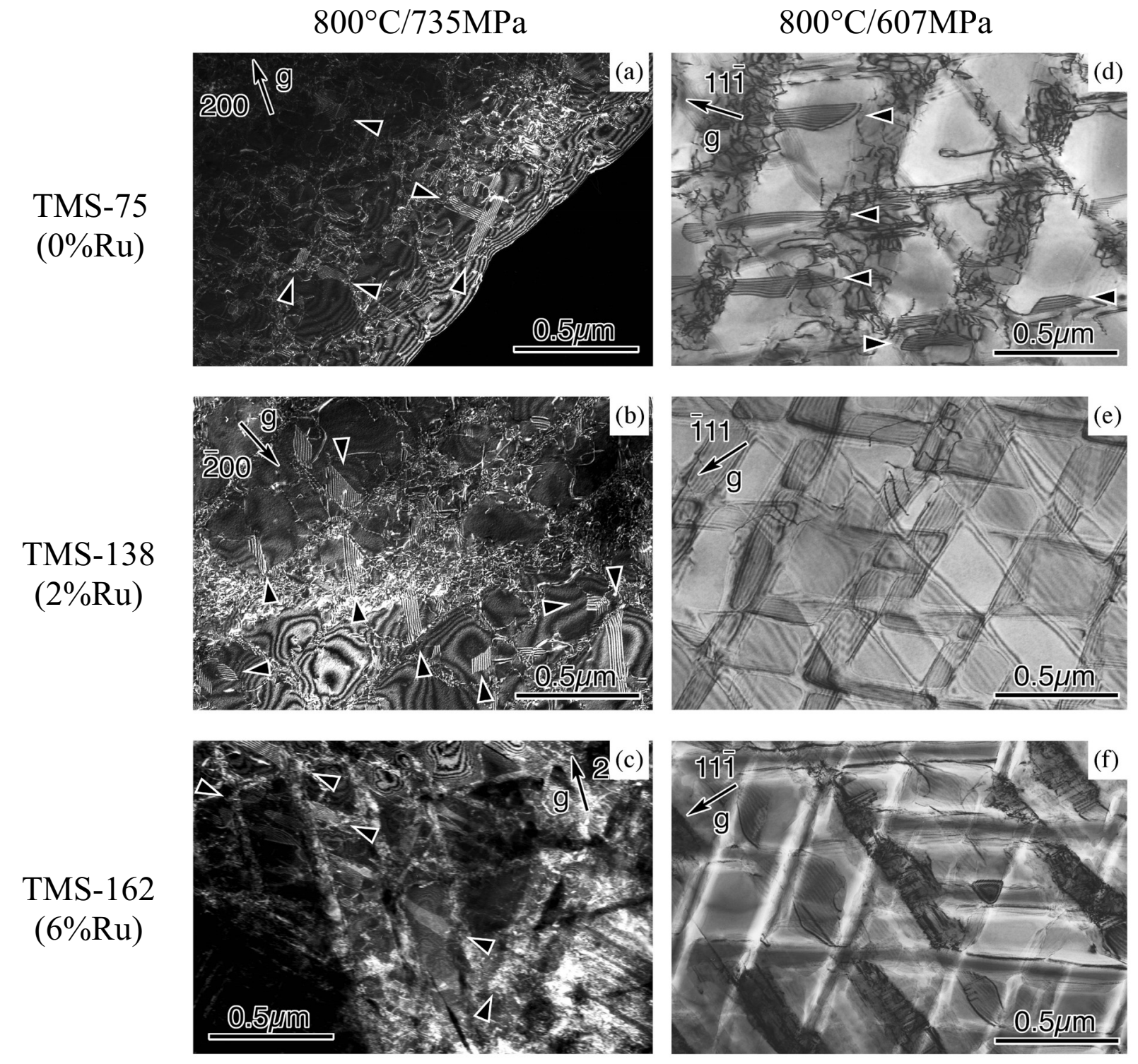

\section{e)}

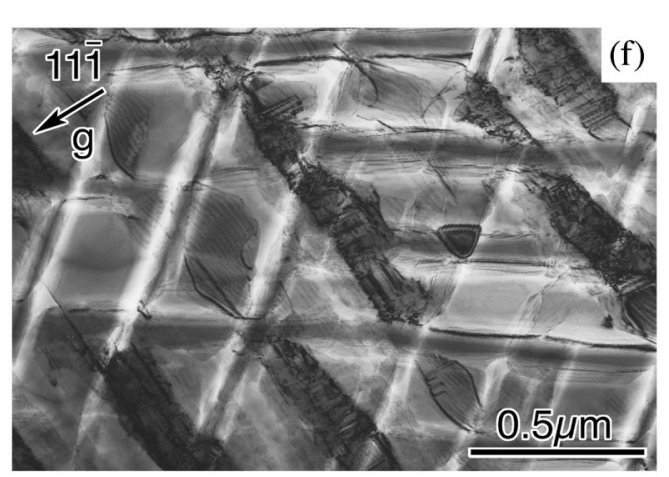

Fig. 10 Super stacking faults (indicated by arrows) in $\gamma^{\prime}$ phases were observed in ruptured specimens. (a) TMS-75, (b) TMS-138, and (c) TMS-162 tested at $800^{\circ} \mathrm{C}$ and $735 \mathrm{MPa}$, and (d) TMS-75, (e) TMS-138, and (f) TMS-162 tested at $800^{\circ} \mathrm{C}$ and $607 \mathrm{MPa}$. 


\subsection{Moderate-temperature moderate-stress creep}

Since a rafted $\gamma / \gamma^{\prime}$ structure was also formed in TMS-162 under the creep condition of $1000^{\circ} \mathrm{C}$ and $245 \mathrm{MPa}$, the creep mechanism discussed above should play a considerably important role. Although the $\gamma / \gamma^{\prime}$ interfacial dislocation density is higher in the present condition, the minimum creep rate is larger than that at $1100^{\circ} \mathrm{C}$ and $137 \mathrm{MPa}$. This is because the higher tensile force can supply a larger driving force for the dislocation to pass through the $\gamma$ channels in the rafted structure. On the other hand, the dislocations can easily combine to form superdislocations and penetrate through the $\gamma / \gamma^{\prime}$ interfacial dislocation networks.

Generally, superdislocations with Burgers vector $\mathrm{b}=<001>$ appear at the high-temperature creep condition [17]. In our investigation for TMS-138 at the creep condition of $1100^{\circ} \mathrm{C}$ and $1150^{\circ} \mathrm{C}$ under the stress of $137 \mathrm{MPa}$, it was found that the density of this kind of $<001>$ superdislocation becomes higher with an increase in the temperature [9]. At the present creep condition $\left(1000^{\circ} \mathrm{C}, 245 \mathrm{MPa}\right)$, although the creep temperature is relatively low, the superdislocations with Burgers vector $b=<001>$ account for a considerable portion in the ruptured specimen compared with the creep at $1100^{\circ} \mathrm{C}$ and $137 \mathrm{MPa}$. The high stress should promote the formation of these $<001>$ superdislocations. Our observation showed that the $<001>$ dislocation is generated by combination of two interfacial dislocations. It would appear that the higher stress can force the interfacial dislocation to bow out and form this kind of $<001>$ superdislocation.

\subsection{Low-temperature high-stress creep}

As discussed in the first section, the addition of Mo can decrease the SF energy. On the other hand, the addition of Ru has no measurable effect on the SF energy. Since the element Ru has a hcp structure, its addition would probably decrease the SF energy to some extent. Overall, the addition of Mo and $\mathrm{Ru}$ leads to a decrease in the SF energy. For the microstructure after creep at $800^{\circ} \mathrm{C}$ and $735 \mathrm{MPa}$, the appearance of SSFs can be easily understood. However, the disappearance of SSFs in TMS-138 (Fig. 10(e)) and TMS-162 (Fig. 10(f)) cannot be attributed to the increase in the SF energy due to addition of Mo and Ru. In contrast with TMS-75 (Fig. 10(d)), the decreasing number of dislocations and even the disappearance of stacking faults in TMS138 and TMS-162 imply that the addition of Mo and $\mathrm{Ru}$ can depress the multiplication of dislocations in the $\gamma$ channels. As to the effect of both $\mathrm{Mo}$ and $\mathrm{Ru}$, the addition of $\mathrm{Ru}$ is the key for strengthening a superalloy at a low-temperature high-stress creep condition. Here creep data of two superalloys designed in our group show clear evidence for the strengthening effect of $\mathrm{Ru}$ in superalloys; the creep life of TMS- 138 is 103.5 hours at $800^{\circ} \mathrm{C}$ and $735 \mathrm{MPa}$ (Fig. 9), while that of the other alloy TMS-138+ $0.5 \mathrm{wt} \% \mathrm{Ru}$ is 284 hours at the same creep condition. Distinctly, an increment of $\mathrm{Ru}$ by $0.5 \mathrm{wt} \%$ has improved the alloy strength considerably.

\section{Conclusion}

When creep takes place under high-temperature low-stress, the large $\gamma / \gamma^{\prime}$ lattice misfit in the negative by the addition of Mo leads to the formation of a dense interfacial dislocation network. This dislocation network guarantees a superior creep property by preventing glide dislocations from cutting the rafted $\gamma / \gamma^{\prime}$ structure. Strengthening by $\gamma / \gamma^{\prime}$ interfacial dislocation networks is the key for designing superalloys to serve under high-temperature low-stress creep condition. The improved creep properties of the superalloys at low-temperature and high-stress creep condition result from solid solution strengthening by the addition of Ru.

\section{Acknowledgments}

The authors wish to thank Dr. J.C. Wang for calculating the misfit stresses with the finite element model. We would also like to thank Mr. S. Nakazawa for creep test and Mr. $\mathrm{T}$. Yokokawa for providing the data on lattice misfit.

\section{References}

[1] U.S. Patent, No.5482789A (1996).

[2] Y. Koizumi, T. Kobayashi, T. Yokokawa and H. Harada, The 2nd International Symposium, "High Temperature Materials 2001". National Institute for Materials Science, 2001. p. 30. (to appear in a special edition of Mater Sci Eng)

[3] J.X. Zhang, T. Murakumo, Y. Koizumi, T. Kobayashi, H. Harada, Acta Mater., Vol.51, (2003), pp. 5073-5081.

[4] J.X. Zhang, T. Murakumo, Y. Koizumi and H. Harada, J. Mater. Sci., 38 (2003) 4883-4888.

[5] D. Mukherji and R.P. Wahi, Acta Mater., Vol. 44, (1996), pp. 1529-1539.

[6] R. Lagneborg, Scripta Metall., Vol. 7, (1973), pp. 605614.

[7] M. Mclean, Acta Metall., Vol. 33, (1985), pp. 545-556.

[8] T.M. Pollock and A.S. Argon, Acta Metall. Mater., Vol. 40, (1992), pp. 1-30.

[9] J.X. Zhang et al. unpublished work.

[10] C.M.F. Rae, N. Matan, and R.C. Reed., Mater Sci Eng, Vol.A300, (2001), pp. 125-134.

[11] H. Harada, and M. Yamazaki, Tetsu to Hagane (in Japanese). Vol.65, (1979), pp. 1059-1068.

[12] M. Benyoucef, B. Decamps, A. Coujou, and N. Clement, Phil. Mag. A, Vol. 71, (1995), pp. 907-923.

[13] F. Pettinari, J. Douin, G. Saada, P. Caron, A. Coujou, and N. Clement, Mater. Sci. Eng., Vol. A325, (2002), pp. 511-519.

[14] T. Yokokawa, M. Osawa, K. Nishida, T. Kobayashi, Y. Koizumi and H. Harada, Scr. Mater., Vol. 49, (2003), pp. 1041-1046.

[15] T. Yamagata, H. Harada, S. Nakazawa, M. Yamazaki and Y.G. Nakagawa, Superalloys 1984, TMS AIME, pp. 157-166.

[16] Y. Koizumi, T. Kobayashi, H. Harada and T. Yamagata, Proceedings of the Fourth International Charles Parsons Turbine Conference, edited by A. Strang, W.M. Banks, R.D. Conroy and M.J. Goulette, 1997, Newcastle upon Tyne, UK, pp. 697-684.

[17] F.R.N. Nabarro and H.L. Villiers, The Physics of Creep. Taylor \& Francis, London, 1995. 
